\title{
Quality of life among people with high spinal cord injury living in the community
}

\author{
K Whalley Hammell*,1 \\ ${ }^{1}$ Oxbow, Saskatchewan, Canada
}

Study Design: An exploratory, qualitative methodology.

Objectives: To explore perceptions of quality of life (QOL) among community-dwelling people with high spinal cord injuries (SCI) and the factors they identified as contributing to, enabling or constraining the quality of their lives.

Setting: Urban communities on Vancouver Island and in the lower mainland of British Columbia, Canada.

Methods: Semi-structured interviews with both men $(n=11)$ and women $(n=4)$ with complete high SCI (C1-C4). Interpretive analysis was grounded in the themes that arose from the interview transcripts.

Results: Time since injury ranged from 4 to 28 years. The mean current age was 35 years, with a range from 21 to 50 years of age. High SCI disrupted not just a body but an entire biography of plans, daily activities and valued occupations. Initially feeling helpless and useless, the participants were unanimously glad to be alive at the time of the study and several described perceptions of very high QOL. The themes which emerged from the data were over-lapping and inter-dependent and described a process of refocusing values and re-establishing a view of the self as able and valuable following injury. The three primary themes addressed issues of autonomy, the meaningful use of time, and relationships.

Conclusions: The study findings suggest that life with a high SCI can be rich and fulfilling if society is prepared to enable and support this; and that QOL outcomes might be maximized by adopting a biographical orientation to the rehabilitation process.

Sponsorship: This research was funded by a University of British Columbia Graduate Fellowship, a studentship from the Rick Hansen Man in Motion Foundation and a doctoral fellowship from the Social Sciences and Humanities Research Council of Canada.

Spinal Cord (2004) 42, 607-620. doi:10.1038/sj.sc.3101662; Published online 24 August 2004

Keywords: spinal cord injury; quality of life; tetraplegia; outcomes; rehabilitation; qualitative research

\section{Introduction}

Quality of life (QOL) is held to be the ultimate objective of rehabilitation ${ }^{1,2}$ and a substantial body of research has sought to evaluate the QOL of survivors of spinal cord injury (SCI) ${ }^{3,4}$ However, although survival rates are increasing among those people who have the highest cord lesions (C4 and above), ${ }^{5,6}$ a review of the research literature demonstrated that little effort has been expended to determine whether those people who have the most profound degrees of impairment feel satisfied with their lives or perceive their survival to be worthwhile (see Hammell's ${ }^{7}$ review).

*Correspondence: KW Hammell, Box 515, Oxbow, Saskatchewan, Canada S0C 2B0
In the absence of studies to the contrary, it can neither be assumed that perceptions of QOL among those who have complete paralysis below the neck will be similar to those who have lesser degrees of impairment; nor that the factors contributing to QOL will be the same among all people with SCI, irrespective of their level of lesion. Given the paucity of studies exploring the life experiences of people with high SCI, rehabilitation therapists have little information with which to ensure the relevance and usefulness of their interventions. Indeed, an assumption that the purpose of rehabilitation is to achieve a high level of independence in self-care ${ }^{8}$ has often served to deny rehabilitation services to those with the highest cord lesions. 9,10 
Media and case reports indicate that suicide may sometimes be preferred to life with a high $\mathrm{SCI}^{11,12}$ and this both reflects and reinforces commonly expressed societal views. ${ }^{13-16}$ However, the belief that quality in living is incompatible with a high SCI is not supported by research evidence. ${ }^{6,17-21}$ Nonetheless, in light of evidence that health-care providers believe death to be preferable to life with high $\mathrm{SCI}^{15}$ and because scant information was available on which to ground relevant and useful rehabilitation services for these survivors, it appeared important to understand more about the lives that are being saved in increasing numbers.

Several scholars have outlined the problems of trying to assess or 'measure' $\mathrm{QOL}^{7,22-24}$ and there is increasing recognition of the value of qualitative research methods for exploring individuals' perceptions of the quality of their own lives and the factors they believe contribute to the experience of quality in living following SCI. ${ }^{3,7,24-29}$ Although several researchers have undertaken research to explore QOL among people with SCI using qualitative methods, ${ }^{30-37}$ it appeared that no qualitative research had been undertaken to explore the QOL perceptions of people with high SCI. ${ }^{7}$

Accordingly, this qualitative study was designed to determine whether and how people with high SCI reconstruct lives worth living and the factors they identified as contributing to, enabling or constraining the quality of their lives. For the purposes of this study, quality of life was conceptualized as being the experience of a life worth living.

\section{Methodology}

The intent of this study was to seek to understand participants' own perceptions of the quality of their lives and the factors they felt contributed to or detracted from their QOL rather than striving to fit researcherselected dimensions of their experiences into existing theoretical frameworks or measurement instruments. This required a qualitative approach. Qualitative approaches 'aim to describe the complexity of human experience in its context and emphasize describing daily events of peoples' lives in their own words ${ }^{38}$ (p 304). In addition, qualitative methodology was considered appropriate because little previous research had been undertaken into QOL following high $\mathrm{SCI}^{6,7}$ (thus this study would be exploratory), because a qualitative methodology is appropriate to examine issues that are, by definition, concerned with quality and not quantity (eg QOL) and because it was congruent with the expressed wish of some participants to explain their experiences 'in our own voices'. Qualitative methodology is particularly appropriate when there is likely to be a small number of potential study participants, ${ }^{39}$ as was anticipated in this study.

\section{Participants}

Men and women were invited by letter to participate in the study if they had complete, traumatic SCI at, or above the fourth cervical neurological level, ${ }^{40}$ were at least 2 years postinjury, aged between 20 and 50 years and living in the community in the Lower Mainland of British Columbia or on Vancouver Island, Canada. These criteria were selected to enable comparison with other QOL studies that had designated 'high SCI' or 'high level tetraplegia' as constituting complete lesions at or above $C 4, ;^{6,17,41,42}$ to permit consideration of the impact of gender on the experience of disability (which would be precluded if only one gender was selected for study); and to explore the experience of a relatively homogenous age group (and one most commonly affected by $\mathrm{SCI}^{43}$ ); and who had attained some experience living with this injury. ${ }^{44}$ Potential participants were identified through a method of snow-ball sampling from initial contacts made through a colleague and friend. ${ }^{45}$

\section{Data collection}

Semistructured interviews were undertaken to explore the experience of living with high SCI. Every interview was undertaken by the researcher $(\mathrm{KWH})$. The majority of interviews occurred in the participants' homes (one occurred in a workplace) and each lasted for approximately $1 \mathrm{~h}$. The interviews were guided by issues that arose from my own knowledge and experience of living and working with people who have high SCI, and from issues raised in both academic and autobiographical literatures. The questions were open-ended and were not asked in a rigid order. The primary queries included those listed in Table 1.

By asking all the participants to respond to the same topics, it was possible to compare themes across interview transcripts and identify member-generated

Table 1 Primary interview prompts

Can you tell me about your injury, in terms of what happened, how old you were and when it was?

Could you tell me about life before your injury, what you were doing, what your interests were and so on?

What were your early perceptions of life with a high spinal cord injury?

How do you view your life now?

[If positive] What factors contribute to your satisfaction with life?

What tends to make the 'bad days' bad? (What factors make living with 'quadriplegia' difficult or negative?)

What have been the most meaningful or significant events, or milestones in your life since your injury?

Could you describe for me a typical day: Where you go; what you do; how you do it?

Can you tell me about the experience of having control over your life?

What is important to you in your everyday life?

Who provides your personal care assistance?

Where has funding come from since your injury?

Is there anything else you feel I should know about living with 'quadriplegia'? 
issues and linkages. Thus, each participant was able to cover the same topics and the last people to be interviewed were able to describe their experiences concerning each of the issues without being constrained by an increasingly narrow framework of inquiry.

All except one of the interviews were audio-taped and subsequently transcribed verbatim (one person preferred not to have a recording made). Repeat interviews were undertaken with the first five respondents. These interviews revisited some of the issues that had been discussed earlier, while enabling a more thorough exploration of issues that had arisen during the study.

The study was conducted over a period of several months until the data had become 'saturated', ${ }^{46}$ that is, no new themes were emerging and the themes that had been identified had been confirmed and explored through the repeat interviews.

Congruent with the principle of reciprocity, during the course of the interviews I answered the telephone, wiped away tears, moved arms and legs, performed assisted coughs, passed cups, positioned drinking straws and provided whatever additional information the participants requested, for example, concerning wheelchair cushions, and feminism and disability. Further details of the interview process and researcher positioning may be found in Hammell. ${ }^{45,47}$

\section{Participant involvement}

In an attempt to reflect occupational therapy's clientcentred philosophy ${ }^{48}$ and to respond to the demands of disability activists for accountable, collaborative and 'nonparasitic' research, ${ }^{49}$ efforts were made to ensure some participant involvement in planning the research, analysing the data and identifying locations for findings to be published and made available. ${ }^{45}$ However, this was not participatory research. Power and control remained with the researcher and the involvement of the participants, regrettably, constituted consultation rather than equal participation.

In the early planning stages, I discussed the focus and nature of the research and the issues I planned to address with three people who had high SCI in an effort to ensure the relevance of the study. There was considerable support for the research with one participant commenting: 'I'm glad to see somebody like you doing something like this' and another saying: 'thank you for the study'. Later the perspectives of one of the participants were incorporated into the process of data analysis by asking him to clarify my interpretations and review and comment on categories and themes that I identified in the data. Ideally, all 15 participants would have been included in data analysis and interpretation. Prohibitive logistics and competing claims upon the participants' time and interests prevented me from requesting such a high level of commitment and from demanding further intrusion into their lives.

However, several of the participants demonstrated a keen interest in the research and suggested ways of promoting the findings with a view to bringing about changes in social attitudes and social policies. I was asked to write about the research for various magazines produced by and for disabled people (see Hammell ${ }^{50-52}$ ). It was agreed that a copy of the final report would be given to the local SCI rehabilitation centre; and several people raised the possibility that I should write a book about the study that would be accessible to 'the general public'. I have not yet embarked upon the latter request.

\section{Ethics and consent}

Approval for the study was granted by the Behavioral Research Ethics Board of the University of British Columbia. After reading the Informed Consent Form, each person was offered the choice of signing consent (by holding a pen between their teeth) or stating verbal consent directly onto the audio tape. Consistent with the ethical imperative to respect confidentiality, all names used in this paper are pseudonyms.

\section{Data analysis}

Through a process of writing a line-by-line index of the transcribed interviews, summarizing these by words or phrases and creating a tally of the themes that arose during the interviews, coding categories ${ }^{46}$ were identified that accounted for all the data. Coding categories drew upon recurrent words across the transcripts. For example, the words: 'refocus', 'reframe', 'reconstruct', 'forget what you can't do', 'it took a reframing of values' arose repeatedly and the categories of subject-matter they represented were linked within one theme to describe how participants had refocused their lives after injury. Those sections of the data that related to unique and specific experiences (such as a preinjury history of cocaine addiction) were not included in the analysis. The transcripts were separated into their themes (with some segments being placed in more than one theme) so that the compatibility of the themes could be determined across the transcripts, the frequency of themes could be ascertained and the recurrence of statements could be identified. Following this thematic analysis of the data, the findings were related to the literature and to contemporary theories.

\section{Findings}

Everyone who was invited to participate agreed to do so, representing probably every person in this geographic area who met the inclusion criteria (two additional names were provided - one male and the other female but these people were seriously ill during the study period). Owing to the unusually specific research population, it is impossible to present demographic details about each participant while both respecting their rights to confidentiality and adhering to the ethical commitment that individuals would not be identifiable in reports arising from the research. Participants were both men (11) and women (four) (Table 2). The majority of the participants were white but also included one 
Table 2 The study participants $(n=15)$

\begin{tabular}{|c|c|}
\hline Age at time of study & Mean $=35$; Range $=21-50$ years of age \\
\hline Age at injury & Mean $=22 ;$ Range $=12-44$ years of age \\
\hline Time since injury & Mean $=13$ years; Range $=4-28$ years \\
\hline Lesion levels & $\mathrm{C} 1=4, \mathrm{C} 2=3, \mathrm{C} 3=4, \mathrm{C} 4=4$ \\
\hline \multirow[t]{3}{*}{ Respiratory status } & Independent $=6$ \\
\hline & Glossopharyngeal breathing during day, assisted ventilation at night $=3$ \\
\hline & $\begin{array}{l}\text { Total assistance }=6 \text { (one phrenic nerve pacer, one pneumobelt, both for day-time only; four continuous } \\
\text { ventilation via tracheostomy) }\end{array}$ \\
\hline Gender & Men $=11(74 \%) ;$ women $=4(26 \%)$ \\
\hline \multirow[t]{2}{*}{ Marital status } & Men: single $=7$, married $=3$ (all since injury), Separated $=1$ (since injury) \\
\hline & Women: single $=3$, married $=0$, divorced $=1$ (re-married and divorced since injury) \\
\hline \multirow[t]{2}{*}{ Living situation } & $\begin{array}{l}\text { Shared cooperative }=4 \text {, with family of origin }=3 \text {, alone in own home with personal assistant }=1 \text {, alone } \\
\text { in social housing with personal assistant }=3 \text {, with spouses (and children) }=3\end{array}$ \\
\hline & $\begin{array}{l}\text { One person had temporarily relocated from his own home to an institution due to dispute with funding } \\
\text { agency }\end{array}$ \\
\hline
\end{tabular}

Current occupation $\quad$ Full-time employment $=2$, self-employed $=1$, further education $=5$, other meaningful occupation (volunteer work, painting, computing, family commitments, pursuing legal action) $=7$

Native Canadian, a Chinese-Canadian and an IndoCanadian. The age at injury ranged from 12 to 44, with a mean of 22 years. The number of years since injury varied from 4 to 28, with a mean of 13 years. Among the women, three were single when injured, one was married and has since divorced, remarried and divorced again. All except one of the men were single when they were injured. Three men have married since their injuries. One couple have had two children and another wife was pregnant. The wife of the only man who was married at the time of his injury promptly rejected him, which was a source of profound sorrow, more distressing to him than his injury.

The themes that emerged from the data were overlapping and interdependent (such that the notion of reappraising one's value, for example, was inseparable from the ability and opportunity to 'do'; or from 'relationships'). The themes identified from the transcripts were as follows:

- Refocusing values/reaffirming the value of myself;

- Autonomy, choice and control; and the related issue of deinstitutionalization;

- Meaningful use of time: doing and being;

- Relationships, belonging, support and reciprocity;

- Contextual issues: positive (access to significant economic, physical and social resources) and negative ('fighting the "system" and coping with impairment).

\section{Life disruption}

High SCI had disrupted not just a body but a biography of interests, daily activities and valued occupations: 'My whole life revolved around my physical abilities...from my perspective, Karen, at the time of the injury, the injury was the most devastating, defeating thing that could have ever happened' (Alan); 'I was a major sports nut. I was with the softball team when I got hurt. We played all kinds of sports. I didn't really have a career as such, just a lot of different jobs' (Owen); 'My interests were basically sports. That's it' $(\mathrm{Jal})$; 'Sport was a big part of my life. I was playing soccer semi-professional; and I was skiing - ready to turn professional in skiing that year' (David); 'I was in a band. I used to play guitar. I was really interested in acting' (Luke); 'I hauled explosives right from Alberta to the Yukon, the NorthWest Territories - all over, and just before I broke my neck I was going to take a course on the use of explosives themselves... That's what I had planned to do and then it all came to a stop when I had the motor vehicle accident' (Matthew); 'After the injury, everything changed' (Nicholas). Katherine described the illusion of life's predictability prior to injury: 'You took everything for granted: your health, your independence - you sort of assumed you had...the right to a certain sort of dream lifestyle'.

There were comments that linked the loss of physical ability with an apparent loss of value. For example, Alan explained that immediately following injury: 'There didn't seem to be any value to my life... because my value as I saw it, had been stolen with the injury: because I was a hockey player, an athlete, and my value was physical and that was me. It took a lot of reframing my life and my values before I could see that life was worth it... I felt so useless, I seemed so dependent. I felt so dependent and the bottom line is that you just felt like you were taking all the time, you weren't giving, and I think it's inherent in all of us that we need to be able to contribute. We need to be able to give back'.

\section{Institutionalization}

Among the 15 study participants, eight had experienced prolonged institutional confinement. Four of these individuals had been instrumental in forcing policy 
changes in British Columbia such that discharge to selfmanaged community living is now the norm in this Canadian Province. (For details, see Hammell ${ }^{53}$ and Zejdlik and Forwell. ${ }^{54}$ ) For this reason, those who had been injured more recently did not share the experience of institutionalization, but for those who did, this was a recurring theme within their narratives.

'It's a depressing place to live when you're 19 years old, or any age: 30 beds all in one room... It was hell really... They just warehoused us in an institution and we fought very hard to get out of that and they said at first 'you'll never do it. You'll live the rest of your life in an institution'. And for me, and a few other fellows, we thought that wasn't good enough. We wanted more of a quality of life' (David). 'I was kind of scared that I might be stuck in institutions for the rest of my life... and that was really scary because you had no freedom in there, no individuality, and you weren't really treated like a real person...it's just a cesspool of humanity ... and just seeing how other people are treated... a lot of them had speech impediments and, you know, can't really fend for themselves and they're really at the mercy of the staff' (Luke); 'We were basically considered second or third class citizens and we were subject to a lot of denigration and abuse... I wanted to leave the extendicare unit that I was in SO BADLY that it became less important to me that I had a [high] spinal cord injury than where I was' (Beth); 'I think all patients who've been in institutions for prolonged periods are quite aware of the overwhelming controls and attitudes' (Nicholas); 'There was a penitentiary feeling...they didn't need actual bars on the windows "cause nobody was going to escape, but it was like a prison in every other sense' (Owen). 'We had no independence - and we were being given to, we were taking and...everyone needs to be able to contribute something and there was no opportunity within [the institution] to contribute...I could sleep for eighteen hours, eat for two, and that makes twenty, so then I could just put up with the other four' (Alan). Colin was asked what his greatest fear for the future would be. Without a moments' hesitation he responded: 'Fear? Growing old and winding up back in the institution'.

Since leaving institutional custody the participants' lives have come to resemble those of other members of society. Several have married, some have fathered children, some have attained university degrees or are currently studying for academic or professional qualifications. Some are employed, full-time, others volunteer or pursue artistic, literary or business endeavours. All these life-enhancing accomplishments were contingent upon the opportunity to live in the community with selfmanaged assistance.

\section{Community living: perceptions of $Q O L$}

Although the intent of this qualitative study was to identify common themes and experiences rather than to present a series of disconnected biographies, the perceptions of each participant to the crucial, yet rarely posed question - how do you view your life now? - are worth presenting individually. Alan: 'I would have traded my life for absolutely anybody's when I first got injured. Anybody! Anybody. Anybody - who could walk. Because that was so much the focus of my life. But I have to say now, that I wouldn't trade my life for anybody's! Life is RICH ... Life is really valuable'. Beth: 'I have an EXTREMELY - I have an exceptional quality of life. I'm not saying that I'd wish not being able to move my arms or legs on someone - on my worst enemy but, I mean, I've been able to carve out a life for myself, with help of course, that is really good. It's better than the life I had before, I think. Now I've certainly got a wider acquaintanceship and more interests'. Colin: 'well, [prolonged pause] it's fine. There's a lot of things that I miss of course, but if you concentrate on what you are able to do and focus towards that, and forget about what you're not able to do, it's a lot easier'. David: 'Those were great years before my injury, and I really enjoyed them... but I wouldn't trade my life for anybody's now you know. Although for a few years there I sure would have... I've got flexibility and it's great! I really feel that I've got a wonderful lifestyle... It's great! It's my life and it's pretty wonderful! And it's tough at times, but then, you know, what isn't that's worthwhile?'. Eric - who was the only person who appeared to find my 'deeper' questions rather odd - mused: 'Oh, I guess it's pretty rewarding. I keep pretty busy - I've been at this for quite a while [13 years] so I guess I don't even really give it that much thought. Like anybody else I guess, you have good days and bad days'. Felix: 'I'm quite content - always looking for more, always looking to win the lottery! Maybe one of these days I could get a job and work parttime... maybe something will come up and I'll be able to go teach [computing] a little bit, just to keep a little more active, you know, do something a little different: a change of scenery'. Graham: '[my life is] a little on the slow side right now, but that's fine with me. I'm enjoying myself. I've got good people around me and the location is great... and I think my quality of life now is quite good. I'm very happy with the way things are'. Heather: 'It's good; for the most part I have good days, occasionally, you know, through the years I've had some bad times where I kind of get a little depressed but I also realize that able-bodied or not, everyone gets down'.

Whereas the majority of the participants contrasted their current lives with former, able-bodied lives that were fulfilling and spontaneous, Ingrid continually reflected back on a past clouded by domestic abuse (which was also the cause of her SCI): 'My life is very full right now and I feel happy where I'm at. In an abusive relationship, I had no control. I was isolated. I had no friends and the difference today is I feel like I have more control over my life and... it feels good to be able to go where I want to and do what I want to and have the choices in my life - and make them - and not have to be abused for it, or, you know, told that 'No you can't' and be stuck at home all the time. I'm never home now and it's great. I love to be out and meeting people. 
I'm a people person and I like to be out in the community'. Jal: 'Oh, I'm up and down. But overall, I'm glad I'm living. Yeah, life is not bad'. Katherine: 'I assume everybody thinks at first, like, 'How am I going to live like this, it just seems so hopeless' but then at the same time, you realize you have no choice, [and] you never really know what you're capable of...I mean, I have bad days and my better days and I find a lot of meaning in the work I'm doing at school, so that helps a lot'. Luke: 'my injury gave me the opportunity to get in touch with myself and who I was and to develop myself mentally and spiritually and I think I became a stronger person'. Matthew: 'Oh, I'm happy. I've got complaints just like everyone else. I do get depressed from time to time, which I imagine everybody does, whether they're walking or in the chair'. Nicholas said he was: 'glad to be alive'. Regrettably, the tape failed at this point, but from the notes made immediately following each interview I reported that he had experienced a profound change in values following injury, focusing entirely upon his children, reading and studying philosophy. Owen: 'It's definitely worth it. And I wouldn't paint a picture of a big bowl of roses because there's ups and downs just like any person... but there's still so much to see, so, it IS good and I'd be willing to tell that to anybody. Anybody that wanted to hear it. There's a lot of really great things going on...I've got kids and I've got my wife and responsibilities and these are all things that for the most part hold my life together'.

The highest appraisals of QOL were made by those among the group who had lived the longest with SCI (eg Alan, Beth, David). The least enthusiastic responses were made by those who had lived with SCI for less than 6 years (Felix, Jal, Katherine). Further, Colin, Felix and Graham were all living in cooperative housing where six people with severe physical impairments shared two care assistants. All agreed that the care was excellent and ample, but the inability of the assistants to leave the building effectively confined the residents to their home and limited their life opportunities. I believe this is illustrated in their appraisals of their current lives.

Despite many positive appraisals of quality in living with high SCI, this is not an easy life. When Owen was on the respiratory care unit after his injury, Alan wheeled over to his bed (he had been injured a decade earlier). Owen reminisced: 'Alan said - and I'll always remember this - 'You know, when I look back on the years since my injury, I wouldn't change a thing. I've met so many really wonderful people and I have learned so much, I wouldn't have had it any other way'. I thought 'He's crazy!' but then Alan continued 'But if I had the chance, I'd be out of this chair in a second!' I feel just the same way. I wouldn't change anything. I've met some wonderful people but I'd be out of this chair in a second too!'.

\section{Refocusing values}

SCI precipitated a period of reflection and the participants' thoughtful responses to questions about their lives suggested that this was a subject most had already contemplated. No longer seduced by the illusion of predictability in their lives, the participants had reevaluated their priorities and re-focused their values. Luke explained: 'I didn't have a motorized chair at first so a lot of time was spent sitting around the hallway and [I had] a lot of time to think and be introspective'. David mused along similar lines: 'it's not often that you have that time - and a lot of people don't have that luxury of time to sit and think about what you want to do with life; to think about your goals and who you are and what makes you tick and now, if I died tomorrow... I really feel that I've done everything that I can accomplish as a person'. Katherine had been a keen soccer player before her accident but now found soccer meaningless: 'I kind of wonder now, when I go by the people running round and around and around on the soccer field, I think, 'Oh my God, why did you ever do that?'. Nicholas was the oldest of the participants when he was injured (46) and the most 'successful' in culturally valued criteria of material comforts, employment and social prestige. Since his injury he has entirely rejected his former lifestyle, viewing it as shallow and superficial. Nicholas linked his current time use with his appreciation of life, explaining that studying philosophy has given him insight and a new way of looking at life that he found tremendously fulfilling and richly satisfying.

Alan observed: 'The person you were pre-injury is the person you are going to be postinjury - with different values' and David elaborated: 'I had to learn a whole new way of looking at life again... You have to throw away the way you looked at life. I mean, when you're young everything is how you look, who you're with and how they look.... and it's all very superficial'. David explained that he had ceased focusing upon his physique and 'started looking at the deeper issues in life and realizing what life was all about'. Such reflection also encompassed the value of the 'self': 'It takes a long time to see value and self-worth are continuing and not tied to physical status' (Alan).

\section{Constraints to the experience of quality in living} Those factors identified as detracting from the quality of their lives fell into two categories.

The experience of impairment Management of the recalcitrant body was entwined with every dimension of each of the participants' lives, for example, '[at work] I might need assistance because of my compromised breathing... I might need someone to push on my chest, give me something to eat, keep bringing me fluids, empty my leg bag' (Alan); 'Pressure sores are a constant worry - like you're constantly worrying about your skin... really the biggest drawback is you have no control over your body, and so I'm constantly scared something's going to happen, you know, like having a spasm or I'm going to get dysreflexic in [university] 
class, and I think 'Oh God, how embarrassing' (Katherine). This was also perceived to be a barrier in obtaining employment 'cause sometimes you just can't get out of bed: you may have a pressure sore or not feeling well...it's not as easy as an able-bodied person' (Felix). Eric described the difficulties in coping with his SCI in addition to a full-time job: 'I guess about a year ago I had a little pressure sore.... I kind of got it right about the time I'd started a new job and then I had six weeks of training so I didn't want to miss any of that, so it got a little worse, and then, you know, it was hell getting rid of it...stuff like that can get a little frustrating'.

Fighting the 'system' Three of the study participants described continual difficulties with gaining access to basic services - such as ventilator repairs - that they identified as being the result of 'power games' rather than policy. Owen explained the difficulties he faced in replacing obsolete equipment: 'you've got to go through OTs [occupational therapists], you've got to go through your doctor, got to go through your social worker, four other workers above her, and then 6 months later you may see a 'yes' or a 'no'! Freedom is still extremely limited. There's always somebody winding up to play a bit of a power trip somewhere'.

Beth (who lived in a different city) complained of difficulties similar to those described by Owen. She identified her struggles against 'the system' as an extremely negative component of her life: 'I have to work so DAMNED HARD at keeping my life as it is...I've just got a feeling that there's a deliberate roadblock thrown in my way. I have a feeling that people have good intentions - but they CANNOT see how a person with a [high] spinal cord injury can live a life that's in anyway satisfactory - or that they should be given any opportunity to do that'. David's experiences of dealing with 'the system' extend in the transcripts for many pages and are punctuated by comments such as 'it's a nightmare', 'it's just constantly a battle', 'you get tired of fighting the battles all the time'. David found that his 'case' is reviewed every 6 months; a situation he could not help but find amusing: 'I've fought for basically five years - really, five years! Five years for [medical] supplies! And finally now it's on a six to six month basis, and I don't know if they think I'm going to get better in the next six months!'.

This experience was not universal among the group, nor isolated (or universal) among those receiving financial support from the government. This would seem to support their belief that their efforts to live in the community were thwarted by the 'power trips' of individual gate-keepers rather than with the policies they were empowered to enact. Eventually, each person obtained the wheelchairs, ventilators, attendant care, technical equipment and supplies that they required, confirming that policies existed to support this.

\section{Contributors to $Q O L$}

Autonomy The ability to enact choices and to be in control of one's own life -autonomy- was identified by the participants as being essential for attaining quality in living: 'You have to take control as much as you can... I direct my own care' (Katherine). Once the participants were able to regain control of their everyday lives by directing their own personal care they redefined themselves as 'able'. Indeed, many no longer viewed themselves as 'disabled'. Felix commented: 'I don't really look at myself any different. I just need somebody to be my hands and feet for me'. David observed: 'I don't look at you as able-bodied and me as disabled....We're [all] doing the best we can with what we have'.

Four of the study participants had been instrumental in forcing innovative changes in social policy that have enabled them to hire their own assistants and live where and with whom they choose: 'You're running your own life and there's no set schedule where you have to do certain things at certain times...it's back more to the way things were, when you can come and go and do whatever you like, eat whatever you like, eat when you like...you've got a lot more freedom' (Felix). Nicholas described leaving the institution as 'A burst of freedom. I was beside myself. I couldn't believe it was true'. The success of this model of care enabled others to follow, so that all the study participants lived in the community with support from paid assistants, sometimes supplemented by help from parents or spouses.

Meaningful use of time: 'doing' Engaging in meaningful activities was perceived to fill life with purpose and imbue it with quality: 'You can do a lot and MAKE a quality of life' (David). Ingrid linked her current efforts to up-grade her education with her feelings of selfworth: 'I think it gives me encouragement that I'm doing something good with my life and I can see myself as a different person and I have more self-esteem which is important to me'. The participants identified the importance of 'doing something' to the experience of quality in living and to viewing themselves as capable and valuable. Included within this theme were five elements that are illustrated below by representative comments.

The need to keep busy: 'I think probably when I first got hurt, I felt my life was over, but once you get on with things and get doing different things, you know it's not by any means. You just have to get on with it... I have to be doing something' (Eric); 'I need to be busy' (Ingrid); '[QOL] is about what we can DO!...I've got some really, really interesting projects coming up and so that all keeps me quite busy...I really enjoy my work!... I keep really busy... you just find some sort of challenge and it really keeps you occupied' (David); 'You can maintain a very high quality of life, just the same as before. You might not be able to go out and water-ski or anything 
like that, but there's still quite a few things you can do. It's just however you want to limit yourself, [that] is the only thing stopping you' (Graham); 'I like to see as much as I can and experience as much as I can' (Colin); 'I find a lot of meaning in the work that I'm doing at school' (Katherine).

The need to have something to wake up for: 'Painting is something to look forward to - something to do when I get up' (Colin); '[after a while] you realize that you've got options and you've got something that you can wake up for every day - I've got to DO something today... We all need something to wake up for... I look forward to getting up every morning. There were many years [in the institution] when I didn't, you know, there was nothing to look forward to' (David); 'When I get up... I've got things to look forward to on the computer and stuff like that. I've got things - games that I'm playing and it's fun to keep track of stock market gains and sports pools and different things like that' (Felix).

The ability to explore new opportunities: 'Writing kind of replaced the hole when I couldn't play music anymore...I'd never tried writing until after my accident. It was something totally new' (Luke); 'a lot of doors have opened for me that probably never would have! I know I would never have painted and I REALLY enjoy that... I used to be into sports before my injury and I couldn't do that any more as a way to express myself, so I decided to try artwork and express myself in that way and it became a real passion for me' (David).

The need to envision future time engaged in meaningful activities: 'I'm going for my dreams and goals - and that's school and getting a good education to have a good job' (Ingrid); 'You've got the rest of your life in front of you...you can't spend a lot of time worrying about what you can't do. Figure out what you can do and focus on that' (Eric). Colin countered the trite advice to live 'one day at a time' with his own experience: 'DON'T live day to day. Kind of set yourself goals year to year and realize that it's ok to resign yourself to the fact that you're going to be like this probably for the rest of your life, so work towards that. If something better comes along that's good, but don't depend on it. Work towards your own self-employment or your own self-worth, because you'll regret not doing so if in a few years down the road when you do start taking something like computers or taking school courses or something, you'll be saying 'Oh, why didn't I do this sooner?'... I wasted like the first five or so years - even five or ten years - by just basically doing nothing, getting loaded on weekends, socializing and just kind of really not thinking year to year, just thinking what you're going to do next weekend'. David decided: 'I was going to do as much as I could. No matter how short or how long my life was going to be - I could do something with it and feel good about waking up every day...maybe I was a little naive but I thought I could do a lot with my life'.

The need and opportunity to contribute reciprocally to others: 'We need to be able to contribute. We need to be able to give back' (Alan); 'I'm able to contribute... I can do things that will make a difference for other people with disabilities... I am able to contribute. And I'm able to contribute in a way that's not only meaningful to me, but I've been told it's meaningful to others too' (Beth). 'I think of myself as a scholar, as a historian - not an authority or anything like that but other people come to me for advice, or with questions and it's rewarding to be able to answer a question... or offer an opinion' (Katherine). The ability to contribute was linked to community living: institutionalization had been associated with 'taking' and with dependent, recipient status: 'I could see that I wasn't in the position of just receiving care that was being given, but it was reciprocal... we were used to being dependent [and] we were aware of what it was like to not be of value, and you lose self-esteem; and in the community, it's just the opposite' (Alan).

The perceived need to contribute to others appeared to be both a dimension of being able to 'do' and a dimension of relationships and reciprocity (outlined below).

Meaningful use of time: beyond 'doing' The participants emphasized the importance of time spent in contemplation and in appreciation of things they felt others take for granted - such as nature, sunshine, music, art, a shower, being alone or being with special people - counter-balancing society's emphasis on 'busyness' with a state of introspection and passive enjoyment, that I termed 'being'. For example, having rejected as superficial a former life-style of material comforts and social prestige, Nicholas values time spent in quiet contemplation, reading, looking at paintings and the opportunity to 'sit in solitude - enjoy the fresh air'. Others made similar comments: 'Things that other people [take for granted] - I don't take for granted any more. And the best thing is I can look out of the back window here and watch the birds and watch the wind blow in the wind sock or the trees around' (Owen).

Relationships Strong relationships with special people were identified by the participants as contributing to the experience of life's quality and also comprised an important resource in reconstructing a life worth living and in re-affirming one's value: 'Your family and friends see you as having value and able to contribute even though you may have written yourself off as having no value. They think you are worth it and you see that you are valued and start to value yourself' (Alan); 'it was 
supportive friends and family that enabled me to explore my own direction and see what I could do' (David).

\section{Enabling $Q O L$}

The study participants had drawn upon many physical and technological resources and social policy initiatives in reconstructing their lives in the community following injury. These included power wheelchairs, pressure-relief cushions, mouthsticks, computers with specialised input devices, environmental control systems, in addition to a variety of options for accessible housing, further education and employment, an exceptional accessible public transit system, adequate financial supports and personal care assistance. Nicholas summed up his appreciation for the substantial support that he received: 'there's funds available [and] the technology's available to keep you mobile and healthy. God knows the hospital expense was phenomenal and I'm so glad to live within Canada under a socialized medicine system,... During the three decades that I did work I participated in support of the system and now that I need it, it's working for me'.

\section{Discussion}

Oliver $e a^{55}$ suggested that it may take at least 9 years for people to adjust to life with a SCI in terms of both personal responses and external circumstances. Owing to the widely varying length of time since injury in the present study (4-28 years), the participants were all at different points in their postinjury lives and this research captures only a snap-shot of this evolution for each person. Perhaps lending support to Oliver et al's observations, those participants who had been injured the longest tended to be more positive about their lives than those who had been injured for less than 6 years.

Those people who had spent prolonged periods of time confined within institutions believed such an existence to be incompatible with QOL. It has been claimed that institutional confinement is characterized by powerlessness, low self-esteem, depersonalization, loss of choices and options, lack of fruitful use of time, regulation and restriction, recipient status, lack of legal rights, limited social contact, lack of opportunity to engage in productive occupations, subordination and negative, disrespectful and belittling staff attitudes. ${ }^{56,57}$ These claims were substantiated by the participants in this study.

Autonomy, or the ability to control and direct one's own life, was important in achieving interdependence and was linked by the study participants to the opportunity to live in the community, to direct their own personal care, to make decisions and to act on choices. This finding is supported by the literature: ${ }^{1,58-67}$ 'Controlling one's life is essential to maintaining personal dignity, independence, and quality of life ${ }^{68}$ (p 325). However, 'control is more than choice. People may make choices but have little control to act on these choices. Control is dependent upon opportunities provided by the environment ${ }^{48}$ (p 37), which included in this instance, political and social commitments to equality of opportunity.

The opportunity to fill time doing something personally meaningful was contingent upon community living and was associated with QOL and with a sense of value, competence, ability and self-worth. This supports previous findings $1,17,35,60,61,63,69-72$ and also provides support for occupational therapy's premise: that occupation is a source of meaning, purpose, choice and control and that engagement in personally meaningful occupations contributes to the experience of a life worth living. ${ }^{48}$ However, occupational therapy theory has demonstrated a clear difficulty with differentiating between the concepts 'purposeful', and 'meaningful', sometimes using the terms interchangeably and tending to extol the notion of meaningful occupation while focusing specifically on purposeful, goal-oriented, socially sanctioned use of time and energy in 'doing', congruent with the values and ideology of Western culture. $^{73}$ The findings of this study suggest that the value attached by occupational therapists to purposeful, goal-directed activities may not be universally shared.

When someone sustains a SCI 'it is not just that the person can no longer walk, it is that the actions of life that were enjoyably self-defining are no longer available $^{74}$ (p 205-206). Thompson et al ${ }^{75}$ suggest that people who have sustained a life-disrupting injury, such as a SCI, need to find a new 'I am' as well as a new 'I can'. Corbin and Strauss ${ }^{76}$ proposed that with a supportive social network and appropriate material resources, forms of lifestyle can be adopted that enable a shift from an image of a disabled, helpless self to one of a capable self. The present study identified the importance of being able to contribute to others partners, assistants, families, friends and communities - in reciprocal relationships that foster perceptions of value and competence, connecting and belonging, a finding supported by other researchers. ${ }^{1,32,33,73,77-85}$ The important role that special people had played in encouraging autonomy, affirming value and worth and facilitating engagement in meaningful occupations suggests that the rehabilitation process would benefit from the conscious and deliberate inclusion of friends and families. If relationships with special people provide opportunities for reciprocity and for engaging in meaningful occupations following discharge it makes little sense to exclude these people from the rehabilitation process.

Several previous studies have found engagement in social activities and social interaction to be positively associated with QOL. ${ }^{3,4,58-61,70,71,86-93}$ In this study, it was impossible to differentiate the notion of social activities from the dual concepts of 'relationships' and 'doing'. When the participants spoke of their relationships with families and friends it was frequently in the context of activities: travelling, going out to restaurants, bars, theatres, concerts, etc. Important relationships underpinned the ability to 'do' and contributed to the pleasure of 'doing'. 
The importance of 'being' to QOL (eg appreciating nature or 'small things', being alone or being with special people) has been identified as an important component of living well with a serious illness or impairment ${ }^{77,81,94,95}$ and demonstrates that occupations do not need to be purposeful in order to be personally meaningful. These dimensions of QOL are rarely included in research tools by those who have always taken such pleasures for granted. ${ }^{96}$ It would be difficult for able-bodied researchers to foresee the importance of such experiences as solitude, or having a shower to those people with high SCI who have spent months or years in a 30-bedded room and where choice and dignity are erased by the imbalance of power relationships with able-bodied staff. This highlights the importance of enabling research participants to identify their own QOL 'domains' for meaningful conclusions to be made concerning their QOL. Although some researchers have acknowledged that disabled people put different weighting on various aspects of their lives than able-bodied people, ${ }^{97}$ existing QOL research tools tend not to address this. ${ }^{98}$ The study participants' strong and consistent message - that confinement in an institution is incompatible with quality in living - supports the position of those who reject researcher-imposed QOL measures, which rarely include 'living at home' as a QOL domain.

Although this study provides support for the conclusions of some previous studies, there were several findings for which it did not find corroborative evidence. Pain has been reported to be inversely correlated with high QOL by several researchers ${ }^{64,86,87,92,99}$ but was not identified as an issue by any participant in this study. This may reflect the observation that pain is more common among people with paraplegia than tetraplegia and in people with incomplete versus complete lesions. ${ }^{100}$

Previous researchers have identified linkages between QOL and mobility $3,61,65,88,91$ and finances. ${ }^{62}$ The study participants did not raise any problems in accessing transportation or community facilities, and they acknowledged having adequate financial supports, medical supplies, mobility and technical equipment. Indeed, apart from the complaints about the 'power trips' employed by individual front-line workers, the study participants' community access, mobility and opportunities, financial, technological and personal care supports reflect unusually progressive and visionary social policy initiatives. The degree of quality the participants reported in their lives justifies and validates these initiatives.

The literature surrounding SCI has focused predominantly on loss, reflecting dominant cultural values. Crewe $^{101}$ explored both perceived gains and losses across 20 years of living with SCI, observing that the kinds of gains that people perceive provide an indicator of their values and the meaning that the disability experience has assumed in their lives' ( $p$ 47). Gains related to such dimensions as new opportunities, greater realism, deeper personal relationships and a renewed appreciation for life. Crewe suggests that people who make a good adjustment to the sudden onset of disability are those who can redefine their values, broaden the range of things that are cherished and decrease the emphasis on physique as a measure of the self. These findings are supported by other researchers ${ }^{102,103}$ and were echoed in the present study.

Duggan et $a b^{37}$ observed that adjustment to SCI can be difficult 'because there is no readily retrievable template upon which to anchor expectations for the future life course' ( $p$ 114). The findings of this study suggest that since there is no culturally accepted script for how one 'ought' to live with high SCI each individual had the unusual opportunity to define their own priorities and possibilities. The daily life experiences of the participants therefore ranged between individuals who expressed great satisfaction in being employed full-time or attending university (reflecting prevailing values) and those whose primary occupation and source of profound satisfaction comprised watching their children, volunteering, visiting with family members or reading (contesting dominant social values that dictate what adults of working age 'ought' to do).

Some researchers have reported, perhaps counterintuitively, that people with high lesions have higher self-esteem and are more satisfied with their lives than people with incomplete or lower lesions ${ }^{104-106}$ and that suicide rates among those with minimal impairments following SCI are nearly twice as high as among those with complete tetraplegia ${ }^{107}$ (although the latter finding is not consistent across studies ${ }^{108}$ ). While researchers have been at a loss to explain this paradox, it is possible that an inability to compete on an equal footing with able-bodied peers places particular distress upon those whose residual physical function suggests that this 'ought' to be attempted. People with paraplegia and low tetraplegia may feel compelled to try to live up to societal expectations of employment and physical independence. In a world designed to support the needs of the majority, able-bodied population - in which discrimination and disabling barriers present sometimes insurmountable obstacles to the physically different - these expectations are prohibitively difficult for many people with SCI to achieve.

People with high SCI are exempted by society from participating in normatively valued activities (although they may choose to participate) and perhaps the reality that little is expected liberates them to choose what they will do and what values will inform their choices. Ville and Ravaud ${ }^{109}$ observed that while a failure to recognize the right of disabled people to work is a form of alienation, so is the imposition of work as an inevitable objective for all' ( $p$ 250). Although asserting that 'work is a right for all', Ville and Ravaud ${ }^{109}$ questioned 'whether it should be an objective to be attained at any price' (p 250).

The proportion of men to women (11:4) in this study reflects the prevalence of SCI reported in Western 
countries. ${ }^{43}$ The generally favourable appraisals of QOL expressed by the participants prompts consideration of possible sample bias. However, there is a low prevalence of people with high SCI and the 17 names I was given through the process of snow-ball sampling are likely to include everyone in this geographic area who met the inclusion criteria. Few of the participants maintained contact with any of the others, suggesting that spontaneity of response had not been compromised. It would demand a high degree of credulity to believe that someone whose life was devoid of pleasure would feel compelled to convey a rosy picture of life with such profound impairment. Indeed, it would seem both less contentious and less effort to support rather than contest prevailing cultural discourses that view QOL as incompatible with a high SCI.

It is evident that the participants in this study were not representative of all people with high SCI. In many societies there are few alternatives for people with severe impairments between the extremes of living in institutional facilities and living with unpaid family members at home. The frequent comments that the participants made regarding institutional living suggest that the life experiences of institutionalized individuals would be very different from their own. However, the intent of this research was to examine what kind of life is possible following a high SCI and this required the participation of a group of people who lived in the community. Recent research has begun to explore the kind of life that is still common following this injury: ${ }^{10}$ documenting the experience of institutionalization and consequent marginalization that is a frequent scenario for people with high SCI. ${ }^{37,111}$ More research is required to provide the evidence-base with which to challenge social policy. Recent legislation assuring access to workplaces, transportation and public buildings is of little benefit to those who must reside in institutions. ${ }^{112}$

It has been suggested that metasyntheses of qualitative research into perceptions of QOL among people with SCI would enable researchers to identify how this is assessed and what factors are perceived to contribute to, or detract from the experience of a life worth living. ${ }^{7}$ To accomplish this - and to generate forms of assessment in which people with high SCI are enabled to identify their own QOL domains and their satisfaction with these domains - clearly requires a great deal more qualitative research.

The study findings suggest that QOL outcomes might be maximized by adopting two approaches. First, because the onset of high spinal cord injury is not solely an assault on a physical body but on a life, a biographical orientation to rehabilitation would help to ensure that interventions are relevant to the individual in the context of their lives; and are focused on fostering control and a view of the self as able and competent through engagement in personally meaningful occupations. A biographical approach to rehabilitation incorporates a client-centred approach to goalsetting and decision-making such that interventions are meaningful, relevant and useful, with SCI viewed as one theme within the context of a life. Concerns have been expressed by therapists that this form of practice will demand more time than would more traditional, therapist-centred modes of practice. Autobiographical accounts ${ }^{113,114}$ suggest instead that effective use of therapists' time may, in reality, be less costly; requiring less (but more directed) input and enhancing accountability. Research evidence demonstrates that clientcentred practice leads to improved outcomes and heightened client satisfaction. ${ }^{115}$

Further, it would seem that a focus upon modifying individuals may be less important than efforts to modify environments. Quality in living for this group of people had been enabled by social policy initiatives that included universal health care, direct funding for personal assistants (wherein people with severe impairments receive money directly from the government with which to hire the personal assistants of their choice), accessible public transportation and housing; provision of high technology equipment and sip-and-puff power wheelchairs, access to education and employment options and financial support. Preoccupation with individual dysfunction is clearly an insufficient response to the circumstances of high tetraplegia.

\section{Conclusion}

This qualitative study has demonstrated that people with high SCI can experience quality in their lives and can perceive survival to be worthwhile. Quality in life was found to be dependent upon: the right to live in the community, the opportunity to control one's own life and care, the ability to engage in meaningful and purposeful occupations and the experience of close relationships with families and friends. The study participants had refocused their priorities and transformed the experience of high SCI from apparent helplessness and uselessness to a sense of being able, valuable and capable.

It has been suggested that the rehabilitation team should not only focus on the acquisition of skills to enable people with SCI to get out of bed in the morning, but should also assist them in finding their own reasons for so doing. ${ }^{116}$ To be meaningful and relevant, rehabilitation must assist each individual in achieving control of his or her life, facilitate the exploration of options and opportunities, encourage the involvement of special people and enable each person to find something meaningful to 'do', such that life is filled with both purpose and meaning.

O'Brien ${ }^{117}$ argued that: 'people weave better lives from the resources afforded by individual effort, personal relationships, available opportunities, and help from services'. This research has demonstrated that people who have high spinal cord injuries can weave lives that are rich and fulfilling if society is prepared to enable and support this. 


\section{References}

1 Pain K, Dunn M, Anderson G, Darrah J, Kratochvil M. Quality of life: what does it mean in rehabilitation? J Rehabil 1998; 64: 5-11.

2 Glass CA. Spinal Cord Injury: Impact and Coping. British Psychological Society: Leicester, 1999.

3 Dijkers M. Correlates of life satisfaction among persons with spinal cord injury. Arch Phys Med Rehabil 1999; 80: 867-876.

4 May LA, Warren S. Measuring quality of life of persons with spinal cord injury: external and structural validity. Spinal Cord 2002; 40: 341-350.

5 DeVivo MJ, Ivie CS. Life expectancy of ventilatordependent persons with spinal cord injuries. Chest 1995; 108: $226-232$.

6 Hall KM, Harper B, Whiteneck GG. Follow-up study of individuals with high tetraplegia $(\mathrm{C} 1-\mathrm{C} 4) 10$ to 21 years post-injury. Top Spinal Cord Injury Rehabil 1997; 2: 107-117.

7 Hammell KW. Exploring quality of life following high spinal cord injury: a review and critique. Spinal Cord 2004 in press.

8 Drewes A, Olsson A, Slot O, Andreasen A. Rehabilitation outcome for patients with spinal cord injury. Int Disabil Stud 1989; 11: 178-180.

9 Hammell KW. Spinal Cord Injury Rehabilitation. Chapman \& Hall: London, 1995.

10 Seymour W. Remaking the Body. Rehabilitation and Change. Routledge: London, 1998.

11 Maynard FM, Muth AS. The choice to end life as a ventilator-dependent quadriplegic. Arch Phys Med Rehabil 1987; 68: 862-864.

12 Globe and Mail.. Woman makes plea to end life. Globe and Mail November 29, 1991 Section A:4.

13 Patterson DR, Miller-Perrin C, McCormick TR, Hudson LD. When life support is questioned early in the care of patients with cervical-level quadriplegia. $N$ Engl $\mathrm{J}$ Med 1993; 328: 506-509.

14 Dijkers M. Quality of life after spinal cord injury. Am Rehabil 1996; 22: 18-24.

15 Gerhart KA. Quality of life: the danger of differing perceptions. Top Spinal Cord Injury Rehabil 1997; 2: $78-84$.

16 Zandrow LF. Misguided mercy: hastening death in the disability community. Top Spinal Cord Injury Rehabil 2001; 6: 76-82.

17 Whiteneck GG et al. A Collaborative Study of High Quadriplegia. Craig Hospital: Englewood, CO, 1985.

18 Glass CA. The impact of home based ventilator dependence on family life. Paraplegia 1993; 31: 93-101.

19 Tilton MC, Bach JR, Wang T-G. Life satisfaction measures: comparison of ventilator supported spinal cord injured individuals with those free of ventilatory support. J Am Paraplegia Soc 1993; 16: 253.

20 Bach JR, Tilton MC. Life satisfaction and well-being measures in ventilator assisted individuals with traumatic tetraplegia. Arch Phys Med Rehabil 1994; 75: 626-632.

21 Bach JR, Barnett V. Psychosocial, vocational, quality of life, and ethical issues. In: Bach JR (ed) Pulmonary Rehabilitation: The Obstructive and Paralytic Conditions. Hanley and Belfus, Inc.: Philadelphia, PA, 1996 pp 395-411.

22 Gill TM, Feinstein AR. A critical appraisal of the quality of Quality-of-life measurements. JAMA 1994; 272: 619-626.
23 Dijkers M. Measuring quality of life. In: Fuhrer MJ (ed) Assessing Medical Rehabilitation Practices. The Promise of Outcomes Research. Paul Brookes: Baltimore, MD, 1997 pp 153-179.

24 Dijkers M. Measuring quality of life: methodological issues. Am J Phys Med Rehabil 1999; 78: 286-300.

25 Whiteneck GG. Outcome evaluation and spinal cord injury. Neurorehabilitation 1992; 2: 31-41.

26 Whiteneck GG. Measuring what matters: key rehabilitation outcomes. Arch Phys Med Rehabil 1994; 75: 1073-1976.

27 Fuhrer MJ. The subjective well-being of people with spinal cord injury: relationships to impairment, disability and handicap. Top Spinal Cord Injury Rehabil 1996; 1: 56-71.

28 The Consortium for Spinal Cord Medicine. Outcomes following Traumatic Spinal Cord Injury: Clinical Practice Guidelines for Health Care Professionals. The Consortium and the Paralyzed Veterans of America: Washington, DC, 1999.

29 Johnston M, Nissim E, Wood K, Hwang K, Tulsky D. Objective and subjective handicap following spinal cord injury: interrelationships and predictors. $J$ Spinal Cord Med 2002; 25: 11-22.

30 Bach CA, McDaniel RW. Quality of life in quadriplegic adults: a focus group study. Rehabil Nurs 1993; 18: 364-367, 374.

31 Boswell BB. Exploring quality of life of adults with spinal cord injuries. Percept Motor Skills 1997; 84: 1149-1150.

32 Boswell BB, Dawson M, Heininger E. Quality of life as defined by adults with spinal cord injuries. $J$ Rehabil 1998; 64: $27-32$.

33 Duggan $\mathrm{CH}$, Dijkers M. Quality of life - peaks and valleys: a qualitative analysis of the narratives of persons with spinal cord injuries. Can J Rehabil 1999; 12: $181-191$.

34 Duggan $\mathrm{CH}$, Dijkers M. Etiology, disablement, and quality of life: interpersonal violence versus other causes of spinal cord injury. Top Spinal Cord Injury Rehabil 1999; 4: 65-85.

35 Duggan $\mathrm{CH}$, Dijkers M. Quality of life after spinal cord injury: a qualitative study. Rehabil Psychol 2001; 46: 3-27.

36 Duggan C, Lysack C. How individuals interpret changes in quality of life following traumatic spinal cord injury. J Spinal Cord Med 2001; 24(Suppl 1): S34.

37 Duggan $\mathrm{CH}$, Lysack C, Dijkers M, Jeji T. Daily life in a nursing home: impact on quality of life after a spinal cord injury. Top Spinal Cord Injury Rehabil 2002; 7: 112-131.

38 Spencer J, Krefting L, Mattingly C. Incorporation of ethnographic methods in occupational therapy assessment. Am J Occup Ther 1993; 47: 303-309.

39 Krefting L. Reintegration into the community after head injury: the results of an ethnographic study. Occup Ther J Res 1989; 9: 67-83.

40 American Spinal Injuries Association/International Medical Society of Paraplegia. International Standards for Neurological Classification of Spinal Cord Injury. Author: Chicago, 2000 (revised).

41 Burnham L, Werner G. The high-level tetraplegic: psychological survival and adjustment. Paraplegia 197879; 16: 184-192.

42 Menter R. Introduction to high quadriplegia care. In: Whiteneck GG et al. (eds) The Management of High Quadriplegia. Demos Publications: New York, 1989 pp 1-3. 
43 National Spinal Cord Injury Statistical Centre. Spinal cord injury. Facts and figures at a glance. J Spinal Cord Med 2002; 25: 52.

44 Fuhrer MJ, Carter RE, Donovan WH, Rossi CD, Wilkerson MA. Post-discharge outcomes for ventilator dependent quadriplegics. Arch Phys Med Rehabil 1987; 68: $353-356$.

45 Hammell KW. Representation and accountability in qualitative research. In: Hammell KW, Carpenter C, Dyck I (eds) Using Qualitative Research. A Practical Introduction for Occupational and Physical Therapists. Churchill Livingstone: Edinburgh, 2000 pp 59-71.

46 Bogdan RC, Biklen SK. Qualitative Research for Education. An Introduction to Theory and Methods, 3rd edn. Allyn \& Bacon: Boston, 1998.

47 Hammell KW. Using qualitative evidence to inform theories of occupation. In: Hammell KW, Carpenter C (eds) Qualitative Research in Evidence-based Rehabilitation. Churchill Livingstone: Edinburgh, 2004 pp 14-26.

48 Canadian Association of Occupational Therapists. Enabling Occupation. An Occupational Therapy Perspective. Author: Ottawa, 1997.

49 Stone E, Priestley M. Parasites, pawns and partners: disability research and the role of non-disabled researchers. Br J Sociol 1996; 47: 699-716.

50 Hammell KW. Learning and Living with High Spinal Cord Injuries, Transition. BC Coalition of People with Disabilities: Vancouver BC, 2000 Jan/Feb: 20-21.

51 Hammell KW. High level injury: self-managed care and quality of life. Total Access: Can Paraplegic Assoc 2000; 1: 31-32.

52 Hammell KW. Living from the neck up: society and high quadriplegia. $N$ Mobil 2000; 11: 53-56.

53 Hammell KW. Changing institutional environments to enable occupation among people with severe physical impairments. In: Letts L, Rigby P, Stewart D (eds) Using Environments to Enable Occupational Performance. Slack: Thorofare, NJ, 2003 pp 35-53.

54 Zejdlik C, Forwell S. A PhD in Life: Living with SCI. BC Rehab \& BCPA: Vancouver, 1993.

55 Oliver M, Zarb G, Silver J, Moore M, Salisbury V. Walking into Darkness: the experience of spinal cord injury. Macmillan Press: Basingstoke, 1988.

56 Lorimer EA. Learned helplessness as a framework for practice in long-term care environments. Aust Occup Ther J 1984; 31: 62-67.

57 Dijkers M. Community integration: conceptual issues and measurement approaches in rehabilitation research. Top Spinal Cord Injury Rehabil 1998; 4: 1-15.

58 Decker SD, Schulz R. Correlates of life satisfaction and depression in middle aged and elderly spinal cord injured persons. Am J Occup Ther 1985; 39: 740-745.

59 Schulz R, Decker S. Long term adjustment to physical disability - the role of social support, perceived control and self-blame. $J$ Person Soc Psychol 1985; 48: $1162-1172$.

60 Crisp R. The long term adjustment of 60 persons with spinal cord injury. Aust Psychol 1992; 27: 43-47.

61 Fuhrer MJ, Rintala DH, Hart KA, Clearman R, Young ME. Relationship of life satisfaction to impairment, disability and handicap among persons with spinal cord injury living in the community. Arch Phys Med Rehabil 1992; 73: 552-557.

62 Krause JS. Life satisfaction after spinal cord injury: a descriptive study. Rehabil Psychol 1992; 37: 61-70.
63 Krause JS, Kjorsvig JM. Mortality after spinal cord injury: a four year prospective study. Arch Phys Med Rehabil 1992; 73: 558-563.

64 Krause JS. Adjustment after spinal cord injury: a 9 year longitudinal study. Arch Phys Med Rehabil 1997; 78: 651-657.

65 Franceschini M, Di Clemente B, Rampello A, Nora M, Spizzichino L. Longitudinal outcome 6 years after spinal cord injury. Spinal Cord 2003; 41: 280-285.

66 McNeil CK, Karunas R, Tate DG. Correlations of quality-of-life after spinal cord injury. $J$ Spinal Cord Med 1998; 21: 61-62.

67 Tate DG, Forchheimer M. Enhancing community reintegration after inpatient rehabilitation for persons with spinal cord injury. Top Spinal Cord Injury Rehabil 1998; 4: $42-55$.

68 Maddox S, Menter R. Consumer perspectives. In: Whiteneck G et al. (eds) The Management of High Quadriplegia. Demos: New York, 1989 pp 315-327.

69 Krause JS, Crewe NM. Prediction of long term survival of persons with spinal cord injury: an 11-year prospective study. Rehabil Psychol 1987; 32: 205-213.

70 Krause JS. Survival following spinal cord injury: a fifteenyear prospective study. Rehabil Psychol 1991; 36: 89-98.

71 Glass CA. The impact of home based ventilator dependence on family life. Paraplegia 1993; 31: 93-101.

72 Reynolds F. Exploring the meanings of artistic occupation for women living with chronic illness: a comparison of template and interpretive phenomenological approaches to analysis. Br J Occup Ther 2003; 66: 551-557.

73 Hammell KW. Dimensions of meaning in the occupations of daily life. Can J Occup Ther 2004 in press.

74 Lee Y, Brock S, Datillo J, Kleiber D. Leisure and adjustment to spinal cord injury: conceptual and methodological suggestions. Ther Recreat $J$ 1993; 27: 200-211.

75 Thompson NJ, Coker J, Krause JS, Henry E. Purpose in life as a mediator of adjustment after spinal cord injury. Rehabil Psychol 2003; 48: 100-108.

76 Corbin J, Strauss A. Comeback: the process of overcoming disability. Adv Med Sociol 1991; 2: 137-159.

77 Berterö C, Ek A-C. Quality of life of adults with acute leukaemia. J Adv Nurs 1993; 18: 1346-1353.

78 Lindsey E. Health within illness: experiences of chronically ill/disabled people. J Adv Nurs 1996; 24: 465-472.

79 Schwartz CE, Sendor M. Helping others helps oneself: response shift effects in peer support. Soc Sci Med 1999; 48: $1563-1575$.

80 Laliberte-Rudman D, Yu B, Scott E, Pajouhandeh P. Exploration of the perspectives of persons with schizophrenia regarding quality of life. Am J Occup Ther 2000; 54: 137-147.

81 Bloom FR. 'New beginnings': A case study in gay men's changing perceptions of quality of life during the course of HIV infection. Med Anthropol $Q$ 2001; 15: 38-57.

82 Lyons M, Orozovic N, Davis J, Newman J. Doing-beingbecoming: occupational experiences of persons with lifethreatening illnesses. Am J Occup Ther 2002; 56: 285-295.

83 Pentland W, Walker J, Minnes P, Tremblay M, Brouwer B, Gould M. Women with spinal cord injury and the impact of aging. Spinal Cord 2002; 40: 374-387.

84 Waldie E. Triumph of the Challenged Conversations with Especially Able People. Purple Field Press: Ilminster, Somerset, 2002. 
85 Rebeiro K. How qualitative research evidence can inform and challenge occupational therapy practice. In: Hammell KW, Carpenter C (eds) Qualitative Research in Evidencebased Rehabilitation. Churchill Livingstone: Edinburgh, 2004 pp 89-102.

86 Post M, de Witte L, van Asbek F, van Dijk A, Schrijvers A. Predictors of health status and life satisfaction in spinal cord injury. Arch Phys Med Rehabil 1998; 78: 395-402.

87 Siösteen A, Lundqvist C, Blomstrand C, Sullivan L, Sullivan M. The quality of life of three functional spinal cord injury subgroups in a Swedish community. Paraplegia 1990; 28: 476-488.

88 Putzke JD, Richards JS, Hicken BL, DeVivo MJ. Predictors of life satisfaction: a spinal cord injury cohort study. Arch Phys Med Rehabil 2002; 83: 555-561.

89 Dijkers M. Quality of life after spinal cord injury: a meta analysis of the effects of disablement components. Spinal Cord 1997; 35: 829-840.

90 Ville I, Ravaud J-F. Tetrafigap Group Subjective wellbeing and severe motor impairments: the Tetrafigap survey on the long-term outcome of tetraplegic spinal cord injured persons. Soc Sci Med 2001; 52: 369-384.

91 Pierce CA, Richards JS, Gordon W, Tate D. Life satisfaction following spinal cord injury and the WHO model of functioning and disability. SCI Psychosoc Process 1999; 12: 121, 124-127.

92 Lundqvist C, Siösteen A, Blomstrand C, Lind B, Sullivan M. Spinal cord injuries: clinical, functional and emotional status. Spine 1991; 16: 78-83.

93 Kemp B, Ettelson D. Quality of life while living and aging with a spinal cord injury and other impairments. Top Spinal Cord Injury Rehabil 2001; 6: 116-127.

94 Gloersen B, Kendall J, Gray P, McConnell S, Turner J, Lewkowicz J. The phenomena of doing well in people with AIDS. West $J$ Nurs Res 1993; 15: 44-58.

95 Young JM, McNicholl P. Against all odds: positive life experiences of people with advanced amyotrophic lateral sclerosis. Health Social Work 1998; 23: 35-43.

96 Farquhar M. Quality of life in older people. Adv Med Sociol 1994; 5: 139-158.

97 Stensman R. Severely mobility-disabled people assess the quality of their lives. Scand J Rehabil Med 1985; 17: $87-99$.

98 Day H, Jankey SG. Lessons from the literature. Toward a holistic model of quality of life. In: Renwick R, Brown I, Nagler M (eds) Quality of Life in Health Promotion and Rehabilitation. Sage: Thousand Oaks CA, 1996 pp 39-50.

99 Westgren N, Levi R. Quality of life and traumatic spinal cord injury. Arch Phys Med Rehabil 1998; 79: 1433-1439.

100 Demirel G, Yllmaz H, Gençosmanoğlu B, Kesiktas N. Pain following spinal cord injury. Spinal Cord 1998; 36: $25-28$.
101 Crewe NM. Gains and losses due to spinal cord injury: views across 20 years. Top Spinal Cord Injury Rehabil 1996; 2: 46-57.

102 Keany KC, Glueckauf RL. Disability and value change: an overview and reanalysis of acceptance of loss theory. Rehabil Psychol 1993; 38: 199-210.

103 McMillen JC, Cook CL. The positive by-products of spinal cord injury and their correlates. Rehabil Psychol 2003; 48: 77-85.

104 Gagnon L. La qualité de vie de paraplégiques et quadriplégiques: analyse relative a l'estime de soi. Rev Can Rech Sci Infirm 1990; 22: 6-20.

105 DeVivo MJ, Black KJ, Richards JS, Stover SL. Suicide following spinal cord injury. Paraplegia 1991; 29: 620-627.

106 DeVivo MJ, Stover SL. Long-term survival and causes of death. In: Stover SL, DeLisa JA, Whiteneck GG (eds) Spinal cord injury. Clinical Outcomes from the Model Systems. Aspen Publications: Gaithersberg, MD, 1995 pp 289-316.

107 Hartkopp A, Brónnum-Hansen H, Seidenschnur A-M, Biering-Sorensen F. Suicide in a spinal cord injured population: its relation to functional status. Arch Phys Med Rehabil 1998; 79: 1356-1361.

108 Soden RJ, Walsh J, Middleton JW, Craven ML, Rutkowski SB, Yeo JD. Causes of death after spinal cord injury. Spinal Cord 2000; 38: 604-610.

109 Ville I, Ravaud J-F. Work, non-work and consequent satisfaction after spinal cord injury. Int $J$ Rehabil Res 1996; 19: 241-252.

110 Holcomb LO. Community reintegration and chronic spinal cord injury. SCI Nurs 2000; 17: 52-58.

111 Putzke JD, Richards JS. Nursing home residence. Quality of life among individuals with spinal cord injury. $A m J$ Phys Med Rehabil 2001; 80: 404-409.

112 Tanzman MR. The campaign for a national personal assistance for independent living program. SCI Psychosoc Process 1991; 4: 98-99.

113 Hansen R, Taylor J, Rick H. Man in motion. Penguin: Markham, Ont, 1988.

114 Murphy RF. The Body Silent. New York: WW Norton, 1990.

115 Law M. Does client-centred practice make a difference?. In: Law M (ed) Client-centered Occupational Therapy. Slack: New Jersey, 1998 pp 19-27.

116 Trieschmann RB. Spinal Cord Injuries - Psychological, Social and Vocational Rehabilitation, 2nd edn. Demos Pub: New York, 1988.

117 O'Brien J. Developing high quality services for people with developmental disabilities. In: Bradley V, Bersani $\mathrm{H}$ (eds) Quality assurance for individuals with developmental disabilities. Baltimore: Paul H Brookes, 1990. 